\title{
Ameliyat Sürecinde Uygulanan Sıvı Tedavisi Yöntemleri
}

\author{
Fluid Treatment Methods Implemented in Perioperative Periods
}

\author{
Dilek ÇíLINGİR ${ }^{\mathrm{a}}$ Perihan ŞİMŞEK ${ }^{\mathrm{b}}$
}

\begin{abstract}
ÖZET Ameliyat sürecini kapsayan dönemde uygun sıvı tedavisinin sağlanması, artan metabolik gereksinimlerin karşılanması ve ameliyat sonrası dönemde komplikasyonların önlenmesinde önemli role sahiptir. Genel olarak ameliyat sürecinde sıvı dengesinin sürdürülebilmesi için serbest ya da kısıtlayıcı olarak adlandırılan sıvı tedavisi yöntemleri uygulanmaktadır. Bu yöntemler, bilinen ya da tahmin edilen sıvı kayıplarının hesaplanması ve karşılanması esasına dayanmaktadır. Son yıllarda yapılan çalışmalar, bu yöntemlere göre uygulanan sıvı tedavilerinin aşırı ya da yetersiz olabildiğini ve sıvı yüklemesi ya da hipovolemi gibi sorunlara neden olabildiğini göstermektedir. Günümüzde tüm bu sorunların önlenebilmesi için ameliyat sürecini kapsayan dönemde bireye özgü hedefe yönelik sıvı tedavisi önerilmektedir. Bireye özgü hedefe yönelik sıvı tedavisinde uygulanacak sıvının miktarı ve cinsi hastaların bireysel özellikleri dikkate alınarak seçilmekte ve tedavi belirlenen hemodinamik ölçütlerin rehberliğinde uygulanmaktadır. Bu makalede, ameliyat sürecini kapsayan dönemde uygulanan sıvı tedavisi yöntemlerine ilişkin bilgi sunulmaktadır.
\end{abstract}

Anahtar kelimeler: Ameliyat süreci, cerrahi hasta, izlem, sıvı tedavisi

\begin{abstract}
Ensuring adequate fluid therapy in the perioperative period have a significant role on meeting the increased metabolic requirements and the prevention of postoperative complications. In general fluid treatment methods called as restrictive or liberal have been implemented for maintaining fluid balance in the perioperative period. These methods are based on calculation of the known or estimated fluid loss. In recent researches have shown that implemented fluid therapy according to these methods may be excessive or insufficient and may cause problems like fluid loading and hypovolemia. Today to avoid all these problems, individual goal directed fluid therapy is recommended in perioperative period. In individual goal directed fluid therapy amount and type of fluid to be applied have been selected cosidering individual characteristics of patients and treatment have been implemented under the guidance of determined hemodynamic criteria. In this article, information concerning the implemented fluid treatment methods for surgical patients in the perioperative period is presented.
\end{abstract}

Key words: Perioperative period, surgery patient, monitoring, fluid therapy

\section{Giriș}

Cerrahi girişimler kanama, ameliyat öncesi aç kalma süresi ve anestezik ilaçlara bağli gelişen vazodilatasyona bağlı olarak bedenden sıvı kaybına ve damar içi hacminde yetersizliğe neden olabilmektedir. ${ }^{1,2}$ Cerrahi girişim nedeniyle gelişen sıvı kaybını önlemek ya da en aza indirebilmek için, ameliyat olacak hastalara ameliyat öncesi, ameliyat suras1 ve ameliyat sonrası dönemi kapsayan cerrahi süreç boyunca sıvi tedavisi uygulanmaktadır. Sıvı uygulamasının amacı, sıvı yüklenmesine ve dehidratasyona neden olmadan sivi kayılarının karşılanması, dokulara yeterli besin ve oksijenin sağlanması için gerekli kan basıncının sürdürülmesidir. ${ }^{3,4}$ Ameliyat sürecini kapsayan dönemde, bu amaç doğrultusunda farklı sıvı tedavisi yöntemleri uygulanabilmektedir. Bu derlemenin amac1, güncel literatür ışığında ameliyat sürecinde uygulanan sıvı tedavisi yöntemlerinin değerlendirilmesidir.

Ameliyat sürecini içeren dönemde uygulanacak sıvı tedavisi konusunda yıllardır süregelen bir tartışma söz konusudur. Sıvı uygulamasının dayandırıldığı bilimsel ilkelerin yeni yapılan çalışmalar sonucunda değişmesi, bu tartışmaların temel nedenleri arasında gösterilmektedir. ${ }^{5}$ Geçmiş yıllarda büyük abdominal ameliyatlar sirasinda bedenden hava yolu, cilt ve cerrahi alandan buharlaşma ile kaybedilen sıvı miktarının karşılanmasinda (beden ağırlığ $1+40) \mathrm{kg} \mathrm{X} 1(\mathrm{ml} / \mathrm{kg} / \mathrm{sa})$ formülü kullanılmaktayd1. ${ }^{6}$ Ancak 1977 yılında yap1lan deneysel bir çalışmada, bir yetişkinin uyanık olduğu zamanlarda buharlaşma yolu ile kaybettiğ $i$ sıvı miktarının yaklaşı $0,5 \mathrm{ml} / \mathrm{kg} / \mathrm{sa}$ olduğu ve büyük abdominal ameliyatlar sirasında bu kaybın yaklaşık iki katına katına çıkabildiği $(1 \mathrm{ml} / \mathrm{kg} / \mathrm{sa})$

Geliş Tarihi/Received:26-09-2016 / Kabul Tarihi/Accepted:27-12-2016

a Doç. Dr, Karadeniz Teknik Üniversitesi Sağlık Bilimleri Fakültesi, e-posta: dilekcilingir1@yahoo.com

b Arş. Gör. Balıkesir Üniversitesi Sağlık Yüksekokulu, p_simsek19@hotmail.com

Sorumlu yazar /correspondence: Doç. Dr. Dilek Çilingir, Karadeniz Teknik Üniversitesi Sağlık Bilimleri Fakültesi, Karadeniz Teknik Üniversitesi Sağlık Bilimleri Fakültesi Ortahisar/Trabzon Merkez/Trabzon

dilekcilingir1@yahoo.com 
saptanmıştır. ${ }^{7}$ Ayrıca sıvı tedavisinin planlanmasında, sıvıların periton ve plevra boşluğu gibi üçüncü boşluk olarak adlandırılan alanlarda birikmesi sonucunda damar içinden kaybedilen sıv1 miktarının yerine konması kuralı terk edilmekte$\operatorname{dir}^{5,8} \mathrm{Bu}$ durumun nedeni, yapılan çalışmaların cerrahi girișim nedeniyle üçüncü boșluğa sıvı birikimi olmadığını; sıvı geçişinin damar duvarındaki glikokaliks yapının travmatik inflamasyon ya da hidrostatik basınç artışı gibi nedenlerle etkilenmesi sonucunda damar içinden hücreler arası alanlara doğru olduğunu göstermesidir. ${ }^{9}$

Günümüzde ameliyat sürecinde uygulanması gereken sıv1 tedavisine ilişkin çalışmalarda serbest (Liberal), kısitlayıc1 (Restrictive) ve bireye özgü hedefe yönelik sıvı tedavisi yöntemleri üzerinde durulmaktadır. ${ }^{10,11}$ Ancak serbest ve kisitlayıcı sıvı tedavisi yöntemleri için yaygın olarak kabul edilen bir tanım bulunmamaktadır. Bir çalışmada kısıtlayıcı olarak kabul edilen bir yöntem bir diğer çalışmada serbest yöntem olarak nitelendirilebilmektedir. Çalışmalarda çoğunlukla, genelde uygulanan sıvı tedavisi yönteminin, standart ya da serbest yöntem olarak adlandırıldığ rın yaklașık \% 10 ' dan azının uygulandığı sıvı tedavisi yönteminin kısıtlayıcı sıvı tedavisi olarak kabul edildiği bildirilmektedir. ${ }^{6,12}$ Serbest ve kısıtlay1cı sıv1 yöntemini karşılaştıran çalışmalarda, ameliyat öncesi ve sonrası dönemlerin tanımları, kullanılan sıvıların türü, ek sıvı uygulama durumları ve yöntemin etkinliğini değerlendirme ölçütlerinin farklılık göstermesi, çalıșma sonuçlarının yorumlanmasını güçleștirmektedir. ${ }^{10,13}$

\section{Sıvı Tedavisi Yöntemleri Serbest Sıvı Tedavisi}

Ameliyat sürecini içeren dönemde sıvı tedavisine ilişkin geleneksel yaklaşım, "serbest infüzyon" olarak da bilinen büyük hacimde kristalloid sıv1nın intravenöz yolla uygulanmasıdır. ${ }^{13} \mathrm{Bu}$ yöntemde, anesteziden önce sıv1 yüklemesi yapılarak anestezinin neden olduğu vazodilatasyonun doku perfüzyonu üzerindeki olumsuz etkisinin, damar içi hacmin arttırılması yoluyla önlenmesi amaçlanmaktadır. Damar içi hacmin yeterliliğinin değerlendirilmesinde klinik (kapiller dolum zamanı vb.), fizyolojik (nabız, saatlik idrar miktarı vb.) ve biyokimyasal (baz fazlalığı, serum laktat düzeyi vb.) ölçütler kullanılmaktadır. ${ }^{14}$

Serbest sivi tedavisi, gece yarısından sonra aç kalan, osmotik ajanlarla barsak temizliği yapılan, terleme ve üriner yoldan devam eden sıv1 kayıpları nedeniyle dehidrate ya da hipovolemik hastalar için komplikasyon riski taşımamaktadır. ${ }^{15}$
Ancak kanıt düzeyi yüksek yeni çalışmalar, bu uygulamaların sıv1 elektrolit dengesizliklerine yol açması nedeniyle ameliyat öncesi hazırlık için uygun olmadığını ortaya koymaktadır. ${ }^{16}$

Serbest sıv1 tedavisi ile fazla miktarda sıv1 uygulanması, venöz basınçta artışa ve damar içinden hücreler arası alanlara sıvı geçişine neden olabilmektedir. Bu durum pulmoner ve periferik ödeme; sistemik ve lokal doku oksijenasyonunun azalmasına neden olmaktadır. ${ }^{17}$ Serbest sıvı tedavisinde özellikle kristalloidler kullanıldığında kritik hastalarda kilo artışı, barsak ödemi, mide boşalmasinda gecikme, oral beslenme toleransinda azalma, ameliyat sonrası dönemde ileus, anastomoz hattında sızıntı, koagülasyon faktörlerinin dilüsyonu ve hastanede kalış süresinde uzama gibi sorunlara neden olduğu saptanmıştır. ${ }^{18,19}$ Bununla birlikte, günübirlik cerrahi hastalarında serbest sıvı tedavisi yöntemi kullanıldığında (1-2 lt dengeli kristalloid sıv1s1) ameliyat sonrası dönemde bulantı, kusma, baș dönmesi ve ağrı yakınmalarının azaldığ 1 bildirilmektedir. ${ }^{13,20,21}$

\section{Kısıtlayıcı Sıvı Tedavisi}

Cerrahi hastalarında sıvı tedavisi için kullanılan bir diğer yöntem, kısıtlayıcı sıvı tedavisidir. $\mathrm{Bu}$ yöntem, hipovolemiden kaçınılması şartıyla hastaların gereksinimini karşılayacak en az miktarda siv1 uygulaması olarak tanımlanabilir. ${ }^{22}$ Kisitlayıc1 sıvı tedavisinde hastanın aldığı ve çıkardığı sıvı miktarlarının dengede olması ve siv1 tedavisine bağlı kilo artışından kaçınılması amaçlanır. $\mathrm{Bu}$ amaç doğrultusunda, uygulanacak sıvı miktarı bireyin kilosuna ve cerrahi girișimin türüne göre hesaplanır. ${ }^{20}$

Literatürde kısıtlayıcı sıvı tedavisi ile cerrahi girişim sonrasında ciddi komplikasyon gelişiminde azalma sağlandığını gösteren çalışmalar bulunmaktadır. ${ }^{23,24}$ Bununla birlikte, kisitlayıc1 uygulama kardiyak debide azalma ve splenik yatakta perfüzyon yetersizliği risklerini getirmektedir. $\mathrm{Bu}$ durum, ameliyat sonrası dönemde ileus, sepsis ve çoklu organ yetmezliğine zemin oluşturmaktadır. ${ }^{4}$ Ayrıca kısitlayıcı sıvı tedavisinin ameliyat sonrası dönemde hipovolemiye yol açarak doku oksijenasyonunun azalmasina neden olduğunu bildiren çalışmalar da bulunmaktadır. ${ }^{25,26}$

Ameliyat sürecini kapsayan dönemde uygulanacak sıvı tedavisine ilişkin üzerinde durulan başlıca risk sıv1 yüklemesidir. Sıv1 yüklemesi mortalite ve morbidite ile ilişkilidir. Özellikle gögüs cerrahisi hastalarında serbest sıvı infüzyonu sonucunda olumsuz sonuçların geliştiği görülmüş ve bu hasta grubunda kisitlayıc1 siv1 uygulamas1 
rutin bir uygulama haline gelmiştir. ${ }^{27}$ Ancak günümüzde gögüs cerrahisinde kısıtlayıcı sıv1 yönetiminin hipovolemi, hipoperfüzyon ve akut böbrek yetmezliği ile ilişkisi üzerinde durulmakta ve hedefe yönelik sıvı tedavisinin kullanılması ile daha başarılı klinik sonuçların alındığı bildirilmektedir. $^{28,29}$

Ameliyat sürecini kapsayan dönemde sıv1 tedavisinin kısitlayıc1 ya da serbest sıv1 tedavisi yöntemlerinden hangisine göre uygulanacağına ilişkin farklı öneriler belirtilmektedir. Konuya ilişkin tartışmalar, Shoemaker ve arkadaşlarının çalışması (1973) ile başlamıştır. Shoemaker ve arkadaşları, doku oksijenasyonu normalin üzerinde olan hastaların klinik sonuçlarının diğer hastalara göre daha iyi olduğunu belirlemiştir. Bu sonuçlar, doku perfüzyonu ile klinik sonuçlar arasındaki ilişkinin, ileri çalışmalarla araştırılması gerekliliğini ortaya çıkarmıştır. Ancak uygulanacak sıvının miktarı, türü ve inotropik ajanların uygulanı uygulanmayacağı konularında genel kabul görmüş bir protokolün olmaması, çalışmaların planlanmasını güçleştirmiş ve tartışmalara neden olmuştur. ${ }^{11,30,31}$

Kısitlayıcı ve serbest sıvı tedavisi yöntemlerinin karşılaştırıldığı çalışmalarda, genel olarak k1sitlayıc1 siv1 tedavisi ile komplikasyonlarda azalma sağlandığı bildirilmektedir. Bununla birlikte, serbest sıvı tedavisi ile daha iyi klinik sonuçlara ulaşıldığını ve sıvı tedavisi yöntemlerinin birbirine göre üstünlüklerinin olmadığını belirten çalışmalar da bulunmaktadır. Araştırma sonuçları arasındaki bu farklılıklar, kisıtlayıcı ya da serbest Sıvı tedavisi yöntemleri için farklı tanımların kullanılması ve çalışmalara dahil edilen hastaların Amerikan Anestezistler Derneği (American Society of Anesthesiologists: ASA) ölçütlerine göre farklı risk düzeylerine sahip olması gibi nedenlere bağlanmaktadır. ${ }^{6,20}$

Randomize kontrollü bir çalışmada, 152 elektif abdominal cerrahi hastası kisitlayıcı ve serbest sıvı tedavisi gruplarına ayrılmıştır. Serbest siv1 tedavisi uygulanan gruba ameliyat kesisinden önce bolus infüzyonla $10 \mathrm{ml} / \mathrm{kg}$, ameliyat sürecinde de $12 \mathrm{ml} / \mathrm{kg} / \mathrm{sa}$ Ringer Laktat uygulanmıştır. Kisitlayıc1 sivi tedavisi uygulanan gruba ise ameliyat sürecinde $4 \mathrm{ml} / \mathrm{kg} / \mathrm{sa}$ Ringer Laktat infüzyonu uygulanmıştır. Bu çalışmada kısıtlayıcı sıvı tedavisi yapılan grupta, komplikasyon gelişiminin diğer gruba göre anlamlı düzeyde düşük olduğu, mortalite oranları arasında ise iki grup arasında anlamlı bir fark olmadığı saptanmıştır. ${ }^{18}$

Major abdominal cerrahi uygulanan 61 hasta ile yapılan bir çalışmada, ameliyat sürecini kapsayan dönemdeki kısıtlayıcı (sıv1 miktarı
$<30 \mathrm{ml} / \mathrm{kg} /$ gün) ve serbest (sıv1 miktar1 30$50 \mathrm{ml} / \mathrm{kg} /$ gün) sıvı tedavisi yöntemleri karşılaştırılmıştır. Çalı̧̧mada, kısıtlayıcı sıvı tedavisi ile morbidite ve hastanede kalış süresinde azalma sağlandığı belirtilmiştir. ${ }^{24}$

Elektif kolorektal cerrahi uygulanan 32 hasta ile yürütülen başka bir randomize kontrollü çalışmada, hastalar kısıtlayıcı ve serbest sıvı tedavisi olarak iki gruba dahil edilmiştir. Araştırmada ameliyat sürecini kapsayan dönemde kısıtlayıcı sivi tedavisi grubuna ortalama toplam $1640 \mathrm{ml} \mathrm{ve}$ serbest sıv1 tedavisi grubuna $5050 \mathrm{ml}$ sıv1 tedavisi uygulanmıştır. Çalışmada, kısıtlayıcı sıvı tedavisi uygulanan grupta serbest sivi tedavisi alan gruba göre ameliyat sonrası dönemde pulmoner fonksiyonlar üzerinde daha olumlu sonuçlar sağlandığ 1 ve komplikasyon gelişimi konusunda iki grup arasında anlamlı bir fark olmadığı saptanmıştır. ${ }^{32}$

Diz protezi uygulanan 48 hastayı kapsayan randomize kontrollü bir çalışmada, ameliyat sürecini kapsayan dönemde kısıtlayıcı sıvı tedavisi grubuna ortalama toplam $1740 \mathrm{ml}$ ve serbest sivi tedavisi grubuna ise $4250 \mathrm{ml}$ sivi tedavisi uygulanmıştır. Çalışma sonucunda serbest sıvı tedavisi yönteminin kısıtlayıcı sıvı tedavisi yöntemine göre ameliyat sonrası dönemde istatistiksel olarak anlamlı şekilde hiperkoagülabilite ve kusmada azalmaya neden olduğu ve iki grup arasında hastanede kalış süreleri arasında fark olmadığı bildirilmiştir. ${ }^{33}$

Elektif kolorektal cerrahi geçiren 80 hasta ile yapılan randomize kontrollü bir çalışmada da, ameliyat sonrası dönemde kısıtlayıcı sıvı tedavisi uygulanan gruba 24 saat içinde iki litre su ve 77 mmol Na ve serbest sıvi tedavisi uygulanan gruba gerektiği sürece günde üç litre su ve $154 \mathrm{mmol} \mathrm{Na}$ uygulanmıştır. Çalışmada, iki grup arasında barsak hareketlerinin başlaması için geçen süre ve hastanede kalış süresi yönünden anlamlı bir fark saptanmamıştır. ${ }^{34}$

\section{Bireye Özgü Hedefe Yönelik Sıvı Tedavisi}

Yapılan çalışmalar hem kısıtlayıcı hem de serbest sıv1 tedavisi yöntemlerinin çeşitli komplikasyonlarla ilişkili olduğunu göstermektedir. Özellikle kritik hastalarda, ameliyat sirasinda uygulanan s1vının yetersiz ya da fazla miktarda olması ameliyat sonrası önemli sorunlara neden olabilmektedir. ${ }^{35,36}$ Ayrica hastaların standart bir protokole dahil edilerek sıv1 gereksinimlerindeki farklılıkların göz ardı edilmesi doğru bir yöntem olarak kabul edilmemektedir. $\mathrm{Bu}$ konudaki ideal yaklaşımın, her hasta için gerekli fizyolojik ölçütler değerlendirilerek sıv1 gereksiniminin belirlenmesi olduğu bildirilmektedir. ${ }^{2}$ 
Cerrahi travma kalp debisinin dolayısıyla da dokulara oksijen sunumunun arttırılmasına yönelik fizyolojik bir yanıta neden olmaktadır. Dokuların yeterli düzeyde oksijenlenememesi enfeksiyon, çoklu organ yetmezliği ve ölüm gibi sonuçlara yol açabilmektedir. ${ }^{37} \mathrm{Bu}$ olumsuz sonuçların gelişmemesi için yeterli doku oksijenasyonunun organ hasarı gelişmeden, erken dönemde sağlanmas1 gerekmektedir. Geç yapılan müdahaleler etkisiz hatta zararlı olabilmektedir. Özellikle yüksek riskli hastalarda ve büyük cerrahi girişimlerde ameliyat sırasında ve yoğun bakım ünitelerinde, yeterli damar içi hacmin sürdürülmesi için bireye özgü hedefe yönelik sıvı tedavisi geliştirilmiştir. ${ }^{20}$ Hedefe yönelik sıvı tedavisi "yeterli doku perfüzyonunun sağlanması için kalp debisi ölçümleri rehberliğinde sıvı infüzyonu ve inotropik ajanların uygulanması" olarak tanımlanmaktadır. ${ }^{3,30}$

Bireye özgü hedefe yönelik sıvı tedavisi için uygulanacak sıvının miktarı, türü ve inotropik/vazoaktif ajanlar hastanın yaşı, cinsiyeti, genel sağlığı, cerrahi girişime bağlı riskler ve özellikle hemodinamik durumuna göre belirlenir. ${ }^{4,27} \mathrm{He}-$ defe yönelik sıvı tedavisinin uygulanabilmesi için hipovolemi ve hipoperfüzyon gibi dengesizliklerin doğru tanınabilmesi; vasküler volüm, kardiyak dolum, bölgesel ve genel doku perfüzyonunun değerlendirilmesi gerekmektedir. Bu değerlendirmeler için günümüze kadar en sık kullanılan ölçütler arasında saatlik idrar çıkışı, arteriyel basınç, santral venöz basınç, kalp debisi, sistemik vasküler direnç, venöz oksijen satürasyonu, periferal nabızlar, cilt sıcaklığ 1 ve turgoru yer almaktadır. ${ }^{38,39} \mathrm{An}-$ cak yapılan son çalışmalarda, saatlik idrar çıkışının stresten etkilenmesi nedeniyle kan hacminin belirlenmesinde güvenilir bir ölçüt olmadığı yönündedir. Ayrıca \%15 oranındaki kan kaybının nabız ve kan basıncı değerlerinde herhangi bir değişime yol açmadığı; bu ölçütlerin özellikle hafif düzeydeki hipovoleminin belirlenmesinde yetersiz kaldığı ve bu nedenle intravasküler hacim konusunda güvenilir göstergeler olmadığı bildirilmektedir. ${ }^{40,41}$ Bunun yanı sira hemodinamik durumun takibinde uzun yıllar kullanılan santral venöz basınç ölçümünün, intravasküler hacim konusunda yeterli bir belirteç olmaması ve santral venöz kateter uygulamasının çeşitli komplikasyonlara yol açması nedeniyle günümüzde terk edilmeye başlandığ 1 bildirilmektedir. ${ }^{42}$

Bireye özgü hedefe yönelik sıvı tedavisi, dokulara yeterli besin ve oksijenin sunumunun sürdürülebilmesi amaciyla kardiyak debi ve atım hacmi ölçümü rehberliğinde uygulanan bir yöntemdir. Bu ölçümler için noninvaziv ya da minimal düzeyde invaziv akım tabanlı monitörizasyon yöntemleri kullanılmaktadır. ${ }^{38,39} \mathrm{Bu}$ yöntemlerin başlıcaları dopler özefageal ultrasonografi, nabız kontür analizi, torasik elektriksel biyoempedans ve termodilüsyon yöntemleri olarak suralanabilir. ${ }^{43,44}$ Bireye özgü hedefe yönelik sıv1 tedavisi uygulaması sırasinda yeterli doku perfüzyonunun sağlanıp sağlanmadığı çeşitli ölçütlerin izlenmesi ile değerlendirilir. Bu değerlendirme için sıklıkla kullanılan ölçütler gastrik mukozal $\mathrm{pH}$, serum laktat düzeyi, $\mathrm{ScvO}_{2}$ (Superior venakava yoluyla ölçülen santral venöz oksijen saturasyonu) ve $\mathrm{SvO}_{2}$ 'dir (pulmoner arter yoluyla ölçülen venöz oksijen saturasyonu) şeklindedir. ${ }^{27,45}$ Belirlenen hemodinamik ölçütlerin akım tabanlı monitörizasyon yöntemleri ile izlenmesi ve normal sinırlar arasında tutulması için gerekli girişimlerin yapılmasıyla ameliyat sonrası mortalitede ve morbiditede azalma sağlandığı bildirilmektedir. ${ }^{46-48}$

Bireye özgü hedefe yönelik sıvı tedavisinin diğer sıvı tedavisi yöntemlerine göre hemodinamik dengenin sağlanması, doku perfüzyonunun arttırılması ve ameliyata bağlı komplikasyonların azaltılmasında daha etkili olduğu; hastanede kalış süresinde ve bakım maliyetinde azalma sağladığ 1 bildirilmektedir. ${ }^{30,49-51}$ Özellikle büyük cerrahi girişimlerde, sıvı tedavisinin ameliyat sırasında hemodinamik monitörizasyon eşliğinde ve hastanın gereksinimlerine göre uygulanması önerilmektedir. $^{44}$

Yüksek riskli cerrahi girişimlerde ameliyat esnasında standart sıvı tedavisi ile bireye özgü hedefe yönelik sıvı tedavisinin karşılaştırıldığı 33 hasta ile yapılan bir çalışmada bireye özgü hedefe yönelik sıv1 tedavisi alan grupta (toplam sıvı miktarı ortalama $4618 \mathrm{ml}$ ) komplikasyon gelişimi, hastanede ve yoğun bakım ünitesinde kalış süresi standart sıvı tedavisi alan gruba göre (toplam sıvı miktarı ortalama $1694 \mathrm{ml}$ ) istatistiksel olarak anlamlı düzeyde düşük bulunmuştur. ${ }^{52}$ Kolorektal cerrahi geçiren 100 hasta ile yapılan randomize kontrollü bir çalışmada hastalar bireye özgü sıv1 tedavisi ve kisitlayıcı sıvı tedavisi alan gruplar olmak üzere iki guruba dahil edilmiştir. Ameliyat dönemi ve sonrasını kapsayan çalışma sürecinde bireye özgü hedefe yönelik sıvı tedavisi alan gruba ortalama $2115 \mathrm{ml}$ ve kisitlayıcı sivi tedavisi alan gruba $1500 \mathrm{ml}$ sıvı tedavisi uygulanmıştır. Çalışma sonuçlarına göre, her iki grup arasında komplikasyon gelişimi ve hastanede kalış süresi yönünden istatistiksel olarak anlamlı bir fark olmadığ bulunmuştur. ${ }^{53}$ 


\section{Sonuç ve Öneriler}

Cerrahi süreç kapsamında, uygulanan sıvı tedavisi yöntemleri hastada sıvı kaybına ya da sıvı yüklenmesine neden olmadan kan basıncının sürdürülebilmesini amaçlamaktadır. Bu amaçla, farklı sıv1 tedavisi yöntemleri uygulanmaktadır. Bu yöntemlerden biri olan bireye özgü hedefe yönelik sıvı tedavisinin, büyük cerrahi girişimler ve özellikle yüksek riskli hastalar için en uygun sıvı tedavisi yöntemi olduğu kabul edilmektedir. Risk düzeyi düşük hastalarda ve küçük cerrahi girişimlerde serbest sıvı tedavisi, orta düzeyde cerrahi girişimlerde ise kısıtlayıcı sıvı tedavisi yöntemi güvenle kullanılabilmektedir.

Cerrahi sürecin her aşamasında gerekli hasta bakımını sağlayan hemşireler, ven içi sıvı tedavisi ve hasta monitörizasyonu uygulama-larında da önemli bir sorumluluğa sahiptir. Ameliyat sürecini içeren dönemde, hemşirelik bakımının planlanmasında sivi tedavisi yöntemleri ve bunlara bağlı gelişebilecek komplikasyonların dikkate alınması, isten-meyen sonuçların önlenmesine ve hasta bakımının kalitesinin yükselmesine katkı sağlayacaktır.

\section{Kaynaklar}

1. P. Van Der Linden. Volume optimization in surgical patients Wet or Dry? Acta Anaesthesiologica Belgica 2007;58:245-250.

2. Kayilioglu SI, Dinç T, Sozen İ, Bostanoglu A, Cete M, Coskun F. Postoperative fluid management. World Journal Critical Care Medicine 2015; 4(3):192-201.

3. Navarro LHC, Bloomstone JA, Auler Jr JOC, Cannesson M, Rocca GD, Gan TJ, et. al. Perioperative fluid therapy: a statement from the international fluid optimization group. Perioperative Medicine 2015;4(3):1-20.

4. Kehlet H, Bundgaard-Nielsen M. Goal-directed perioperative fluid management. Anesthesiology 2009;110:453-455.

5. Minto G, Mythen MG. Perioperative fluid management: Science, art or random chaos? British Journal of Anaesthesia 2015;114(5):717721.

6. Rocca GD, Vetrugno L, Tripi G, Deana C, Barbariol F, Pompei L. Liberal or restricted fluid administration: are we ready for a proposal of a restricted intraoperative approach? Bio $\mathrm{Me}$ dical Central Anesthesiology 2014;14:62.

7. Lamke LO, Nilsson GE, Reithner HL. Water loss by evaporation from the abdominal cavity during surgery. Acta Chirurgica Scandinavica 1977;143:279-284.
8. Strunden MS, Heckel K, Goetz AE, Reuter DA. Perioperative fluid and volume management: physiological basis, tools and strategies. Annals of Intensive Care 2011;1(1):2

9. Jacob M, Chappell D, Rehm M. The "third space"-fact or fiction? Best Practice \& Research Clinical Anaesthesiology 2009;23(2):145-157.

10. Holte K. Pathophysiology and clinical implications of peroperative fluid management in elective surgery. Danish Medical Bulletin 2010;57(7):B4156.

11. Bellamy MC. Wet, dry or something else? British Journal of Anaesthesia 2006;97(6): 755757.

12. Rahari NI, Zimmermann J, Schmidt T, Koch M, Weigand MA, Weitz J. Meta-analysis of fluid administration in colorectal surgery. British Journal of Surgery 2009;96: 331-341.

13. Doherty M, Buggy DJ. Intraoperative fluids: how much is too much? British Journal of Anaesthesia 2012;109(1):69-79.

14. Moemen ME. Fluid therapy: Too much or too little. Egyptian Journal of Anaesthesia 2010;26(4): 313-318.

15. Bleier JI, Aarons CB. Perioperative fluid restriction. Clinics in Colon and Rectal Surgery 2013;26(03):197-202.

16. Gustafsson UO, Scott MJ, Schwenk W, Demartines N, Roulin D, Francis N, et.al. Guidelines for Perioperative Care in Elective Colonic Surgery: Enhance Recovery After Surgery (ERAS) Society Recommendations. World Journal of Surgery 2013;37:259-284.

17. Fluid Balance and Acute Kidney Injury: Potential Adverse Effects of Liberal Fluid Therapy. Medscape [Cited 7 June 2016]. Avaible from: http://www.medscape.org/viewarticle/715130_4.

18. Nisanveich V, Feisenstein J, Almogy G, Weissman C, Einav S, Matot I. Effect of intraoperative fluid management on outcome after intraabdominal surgery. Anesthesiology 2005;103:25-32.

19. Yunos NM, Bellomo R, Hegarty C, Story D, Ho L, Bailey M. Association between a chloride-liberal vs chloride-restrictive intravenous fluid administration strategy and kidney injury in critically ill adults. Journal of The American Medical Association 2012;308:1566-1572.

20. Woldby AW, Brandstrup B. Fluid therapy in the perioperative setting a clinical review. Journal of Intensive Care 2016;4:27. 
21. Lambert KG, Wakim JH, Lambert NE. Preoperative fluid bolus and reduction of postoperative nausea and vomiting in patients undergoing laparoscopic gynecologic surgery. American Association of Nurse Anesthetists Journal 2009; 77: 110-114.

22. Zhang J, Qiao H, He Z, Wang Y, Che X, Liang $W$. Intraoperative fluid management in open gastrointestinal surgery: Goal-directed versus restrictive. Clinics 2012; 67(10): 1149-1155.

23. Bundgaard-Nielsen M, Secher NH, Kehlet $\mathrm{H}$. 'Liberal'vs. 'restrictive'perioperative fluid therapy-a critical assessment of the evidence. Acta Anaesthesiologica Scandinavica 2009;53(7):843-851.

24.de Aguilar-Nascimento JE, Diniz BN, do Carmo AV, Silveira EAO, Silva RM. Clinical benefits after the implementation of a protocol of restricted perioperative intravenous crystalloid fluids in major abdominal operations. World Journal of Surgery 2009;33(5):925930.

25.Warrillow SJ, Weinberg L, Parker F, Calzavacca P, Licari E. Perioperative fluid prescription, complications, and outcomes in major elective open gastrointestinal surgery. Anaesth Intensive Care 2010;38:251-265.

26.Futier E, Constantin JM, Petit A, Chanques G, Kwiatkowski F, Flamein R, et. al. Conservative vs restrictive individualized goal-directed fluid replacement strategy in major abdominal surgery: A prospective randomized trial. Archives of Surgery Journal 2010;145(12):1193-1200.

27.Chau EH, Slinger P. Perioperative fluid management for pulmonary resection surgery and esophagectomy. Seminars in Cardiothoracic and Vascular Anesthesia 2014;18(1): 3644.

28.Assaad S, Popescu W, Perrino A. Fluid management in thoracic surgery. Current Opinion in Anesthesiology 2013;26(1):31-39.

29.Searl CP, Perrino A. Fluid management in thoracic surgery. Anesthesiology Clinics 2012;30(4):641-655.

30.Cecconi M, Corredor C, Arulkumaran N, Abuella G, Ball J, Grounds RM, et. al. Clinical review: Goal-directed therapy-what is the evidence in surgical patients? The effect on different risk groups. Critical Care 2013;17(2):1.

31.Shoemaker WC, Montgomery ES, Kaplan E, Elwyn DH. Physiologic patterns in surviving and nonsurviving shock patients. Use of sequential cardiorespiratory variables in defining criteria for therapeutic goals and early warning of death. Archives of Surgery 1973;106: 630636.

32.Holte K, Foss NB, Andersen J, Valentiner L, Lund C, Bie P, et. al. Liberal or restrictive fluid administration in fast-track colonic surgery: a randomized, double- blind study. British Journal Anaesthesiology 2007;99(4):500-508.

33. Holte K, Kristensen BB, Valentiner L, Kehlet H. Liberal Versus Restrictive Fluid Management in Knee Arthroplasty: A Randomized, Double-Blind Study. Anesthesia and Analgesia 2007;105(2):465-474.

34. MacKay G, Fearon K, McConnachie A, Serpell MG, Molloy RG, O’Dwyer PJ. Randomized clinical trial of the effect of postoperative intravenous fluid restriction on recovery after elective colorectal surgery. British Journal of Surgery 2006;93: 1469-1474.

35. Patel S, Lutz JM, Panchagnula U, Bansal S. Anesthesia and perioperative management of colorectal surgical patients - specific issues (part 2). Journal of Anaesthesiology Clinical Pharmacology 2012;28(3):304-313.

36. Vermeulen H, Hofland J, Legemate DA, Ubbink DT. Intravenous fluid restriction after major abdominal surgery: a randomized blinded clinical trial. Trials 2009;10(1):1.

37. E. Bennett-Guerrero. Hemodynamic GoalDirected Therapy in High-Risk Surgical Patients. Journal of the American Medical Association 2014;311(21):2177-2178.

38. Roche AM, Miller TE, Gan TJ. Goal-directed fluid management with trans-oesophageal Doppler. Best Practise Research Clinical Anaesthesiology 2009;23: 327-334.

39. Wilms H, Mittal A, Haydock MD, Van Den Heever M, Devaud M, Windsor JA. A systematic review of goal directed fluid therapy: rating of evidence for goals and monitoring methods. Journal of Critical Care 2014;29(2):204-209.

40. Le Manach Y, Christoph KH, Lehot JJ, Vallet B, Goarin JP, Tavernier B, et. al. Can changes in arterial pressure be used to detect changes in cardiac output during volume expansion in the perioperative period? Anesthesiology 2013;117:1165-1174.

41. Bundgaard-Nielsen M, Ruhnau B, Secher NH, Secher NH, Kehlet H. Flow-related techniques for preoperative goal-directed fluid optimization. British Journal Anaesthesiology 2007;98:38-44.

42. Marik PE, Cavallazzi R. Does the central venous pressure predict fluid responsiveness? An 
updated mata-analysis and a plea for some common sense. Critical Care Medicine 2013;41(7):1774-1781.

43. Trinooson CD, Gold ME. Impact of goal-directed perioperative fluid management in highrisk surgical procedures: a literature review. American Association of Nurse Anesthetists Journal 2013;81(5):357-368.

44. Funk DJ, Moretti EW, Gan TJ. Minimally invasive cardiac output monitoring in the perioperative setting. Anesthesia \& Analgesia 2009;108: 887-897.

45. Romagnoli S, Romano SM, Bevilacqua S, Lazzeri C, Ciappi F, Dini D, et. al. Hemodynamic goal-directed therapy. A review. HSR Proceedings in Intensive Care \& Cardiovascular Anesthesia. 2009;1(1): 54-58.

46. Hamilton MA, Cecconi M, Rhodes A. A systematic review and meta-analysis on the use of preemptive hemodynamic intervention to improve postoperative outcomes in moderate and high-risk surgical patients. Anesthesia \& Analgesia 2011;112: $\quad$ 1392-1402.

47. Benes J, Chytra I, Altmann P, Hluchy M, Kasal E, Svitak R, et. al. Intraoperative fluid optimization using stroke volume variation in high risk surgical patients: results of prospective randomized study. Critical Care 2010; 14(3):R118. doi:10.1186/cc9070.

48. Mayer J, Boldt J, Mengistu AM, Röhm KD, Suttner S. Goal-directed intraoperative therapy based on autocalibrated arterial pressure waveform analysis reduces hospital stay in high-risk surgical patients: a randomized, controlled trial. Critical Care 2010;14(1):R18. doi:10.1186/cc8875.
49. Giglio MT, Maruccin M, Testini M, Brienza N. Goal-directed haemodynamic therapy and gastrointestinal complications in major surgery: A meta-analysis of randomized controlled trials. British Journal of Anaesthesia 2009;103(5): 637-646.

50. Kassim DY, Esmat IM. Goal directed fluid therapy reduces major complications in elective surgery for abdominal aortic aneurysm: Liberal versus restrictive strategies. Egyptian Journal of Anaesthesia 2016;32(2):167-173.

51. Senagore AJ, Emery T, Luchtefeld M, Kim D, Dujovny N, Hoedema R. Fluid Management for Laparoscopic Colectomy: A Prospective, Randomized Assessment of GoalDirected Administration of Balanced Salt Solution or Hetastarch Coupled with an Enhanced Recovery Program. Diseases of The Colon \& Rectum 2009;52:12

52. Lopes MR, Oliveira MA, Pereira VOS, Lemos IPB, Auler JOC, Michard F. Goaldirected fluid management based on pulse pressure variation monitoring during high-risk surgery: a pilot randomized controlled trial. Critical Care 2007;11(5):R100. doi:10.1186/cc6117.

53. Phan TD, An VD'souza B, Rattray MJ, Johnston MJ, Cowie BS. A randomised controlled trial of fluid restriction compared to oesophageal Doppler-guided goal-directed fluid therapy in elective major colorectal surgery within an Enhanced Recovery After Surgery program. Anaesthesia and Intensive Care 2014;42(6):752. 